\title{
GAME ACTION TURNBASE HORROR "SECURITY MAKAM BELANADA" DENGAN UNITY ENGINE BERBASIS ANDROID MENGGUNAKAN METODE A*
}

\author{
Nandaka Dibrayogasta, Suryo Adi Wibow, Renaldi Prameswara \\ Program Studi Teknik Informatika S1, Fakultas Teknologi Industri \\ Institut Teknologi Nasional Malang, Jalan Raya Karanglo km 2 Malang, Indonesia \\ nandakadibra@gmail.com
}

\begin{abstract}
ABSTRAK
Penelitian ini bertujuan untuk membuat game Action Turbase Horror Strategi bebrbasis android. Metode yang di gunanakan dalam permainan ini adalah $A^{*}$. dimana, metode $A^{*}$ dipakai dalam AI (Artificial Intelegency) untuk musuh-musuh di dalam permainan ini. Pada game ini juga bertujuan untuk mengenalkan upacara pemakaman unik, yangada di tiga daerah yaitu Bali, Kalimantan, dan Papua.

A* adalah sebuah metode pencarian jalan terdekat dari posisi awal ke posisi tujuan. Maka dari itu, Metode A* ini sangat cocok untuk di kembangkan dalam permainan "SECURITY MAKAM BELANDA", dimana A* di gunakan pada Ai musush sehingga mereka bisa mendekati pemain dengan jarak terpendek.

Hasil dari penelitian ini adalah sebuah game(permainan) strategi yang dapat menghibur sekaligus mengasah otak yang dapat di nikmati oleh anak-anak dan orang dewasa. Ditambah lagi permainan ini mempunyai sedikit unsur edukasi dimana para pemain dapat mempelajari sedikit tentang upacar-upacara pemakaman yang ada di indonesia.
\end{abstract}

Kata Kunci : Video Game, Action TurnBase,C\#, A*, Android, Unity.

\section{PENDAHULUAN}

Video game bukanlah aplikasi langka ataupun hanya dimainkan beberapa orang. Melainkan video game sudah menjadi hiburan universal bagi hampir semua kalangan dari tua sampai muda, pria maupun wanita. Menurut laporan AppAnnie pada tahun 2017 Indonesia menempati posisi keempat dalam daftar negara dengan jumlah unduhan aplikasi terbanyak di Google Play, naik dari posisi keenam di tahun 2015 setelah berhasil menyalip Rusia dan Meksiko[1]. salah satu genre yang banyak dinikmati adalah Actinon turbase Ini menandakan bahwa masyarakat indonesia sangat menikmati aplikasi video game ini.

Namun pada pengembanganya video game dengan genre ini masih kurang di kembangkan padahal banyak sekali peminat nya. Selain itu, video game bergenre ini juga bukan hanya membuat sipemain(player) merasa terhibur. Tetapi dapat membuat si player untuk berpikir dalam menyelesaikan setiap levelnya karena genre ini membutuhkan strategi untuk menyelesaiakan rintangan di tiap levelnya.

Penelitian mengenai AI A* pathfinding sudah banyak dilakukan dalam game strategi, salah satunya adalah Gideon Adidiprana Tigor Siburian, pada tahun 2017 iya menciptakan sebuah turn-based strategi Role Playing Game menggunakan algoritma A*. video game tersebut dia buat dengan tujuan implementasi dan pengembangan metode $\mathrm{A}^{*}$ pada $\mathrm{AI}$ musuh atau yang biasa di sebut NPC(Non Playebel Charakter) dimana NPC pada game tersebut dapat menentukan jalur terdekat yang dapat di lalui untuk menuju si karakter utama.
Maka dari itu penulis ingin membuat video game Action Horor Strategi yang mengutamakan fun to play dan Mengasah otak. Dimana game yang akan di buat dengan judul "Security Makam Belanda" akan menekankan Action Horor Strategy dengan menerapkan dan berusaha mengembangkan metode pathfinding dan $\mathrm{A}^{*}$. Ditambah lagi penulis ingin memasukkan edukasi sejarah di dalam game yang akan di buat. Dimana setiap kali player berhasil menyelesaikan level, Maka di loading page akan munncul encyclopedia tentang sejarah dan macammacam cara penguburan mayat di seluruh indonesia

\section{TINJAUAN PUSTAKA}

\subsection{Penelitian Terdahulu}

2017, Gideon Adidiprana Tigor Siburian membuat sebuah video game turn-based strategi Role Playing Game menggunakan algoritma $\mathrm{A}^{*}$. video game tersebut dia buat dengan tujuan implementasi dan pengembangan metode $\mathrm{A}^{*}$ pada $\mathrm{AI}$ musuh atau yang biasa di sebut NPC(Non Playebel Charakter). Didalam permainan yang dia buat peraturan yang ada hampir mirp dengan permainan catur. Diaman terdapa empat karakter yaitu sperman, archer, paladin dan hero nya sendiri. Terdapat dua kubu dalam video game yang dia buat. pertama yang di mainkan oleh player dan kedua yang di mainkan oleh AI sebagai lawan si player.[1]

Pada tahun 2015 Andre Lionel Sanjaya dan kawan-kawan nya yang berjumlah dua orang membuat sebuah game Turn Based Strategy Role Playing Game Menggunakan Unity Game Engine. game yang meraka ciptakan memiliki map yang luas dan memiliki permainan seperti game "fireemblem" yang di buat oleh perusahan besar pembuat game 
yaitu "Nintendo" . permainan ini mempunya aturan yang lumayan rumit dimana hero akan berjalan mendatang musuh yang ada di map, kemudian jika si heromenabrak karakter utama maka permain tersebut akan memasuki mode bertarung. Barulah disini turnbased nya di pakai. Disini hero dan enemy akan bergerak secara bergiliran.[4]

Pada tahun 2018 Ronny Setiawan dan kawankawanya membuat sebuah game turn-based yang berbeda dari yang lain yang bernama "GEVANGEN". Dimana turn based nya mengandalkan system gunting,batu, kertas. Yang dimaksud disi adalah permainya bergantung dengan keberuntungan probabilitas. Jadi, di saat hero menyerang enemy ada perbandingan $50: 50$ serangan hero mengenai enemy begitu pula sebaliknya.[5]

Pada tahun 2015, Joseph Dedy Irawan, Sonny Prasetio, Suryo Adi Wibowo, dan Yosep Agus Pranoto menulis sebuah jurnal tentang pembuatan game menggunakan aplikasi Greenfoot. Menurut mereka Greenfoot adalah sebuah aplikasi yang dikembangkan dari lingkungan Java interaktif yang dirancang untuk tujuan pendidikan di sekolah tinggi dan tingat sarjana. Greenfoot dirancang agar dapat membantu dalam pengembangan sebuah aplikasi grafis dua dimensi, seperti simulasi dan permainan interaktif.[6]

\subsection{Dasar Teori}

\subsubsection{Game Engine Unity}

Unity merupakan suatu aplikasi yang digunakan untuk mengembangkan game multi platform yang didesain untuk mudah digunakan. Unity itu bagus dan penuh perpaduan dengan aplikasi yang profesional. Editor pada Unity dibuat dengan user interface yang sederhana. Unity cocok dengan versi 64-bit dan dapat beroperasi pada Mac OS x dan windows dan dapat menghasilkan game untuk Mac, Windows, Wii, iPhone, iPad dan Android[1].

\subsubsection{Genre Action Strategi}

Adalah salah satu genre dalam video game dimana, cara bermainya lebih di tekankan untuk berpikir dalam pengambil keputusan yang paling tepat dalam menyelesaikan masalah dalam game yang player mainkan. Genre ini juga termasuk yang paling banyak di gemari kara selain mengisis waktu luang, juga mengasah otak si player. Genre ini mempunyai dua sub-genre yaitu :

\section{Turn-Based Strategy}

Adalah salah satu sub-genere dari strategi. Dimana dalam genre ini, biasanya player akan mengontrol hero yang berjumlah tiga ataupun lebih. Cara bermainya adalah dengan cara menggerakkan tiap hero secara satu-persatu, setelah si player selesai memerintah dan mengatur strategi barulah musuhnya(AI) ikut mengatur dan berusaha mengallahkan si player.

\section{Real-Time Strategy}

Adalah suatau sub-genre dari strategi dimana dalam game ini pergerakan antara player dan musuh di lakukan secara bersamaan atau(real-time). Jadi player harus berpikir lebih cepat untuk mengantisipasi pergerakan musuh untuk mengalahkanya

\subsubsection{Bahasa Pemrograman C\#}

C\# adalah sebuah bahasa pemrograman sederhana yang digunakan untuk tujuan umum, maksudnya adlaha C\# dapat di gunakan untuk berbagai fungsi seperti pembuatan server dan pembuatan aplikasi destop maupun Adroid.

\subsubsection{Adroid}

Android merupakan salah satu sistem operasi atau operating system berbasis mobile yang sangat banyak di gunakan sekarang ini. Terutama pada telepon pintar (smartphone) ataupun tablet yang di perkenalkan pada tahun 2007.

Android adalah sistem operasi yang dirancang oleh Google dengan basis kernel Linux untuk mendukung kinerja perangkat elektronik layar sentuh, seperti tablet atau smartphone. Jadi, android digunakan dengan sentuhan, gesekan ataupun ketukan pada layar gadget anda.

Android bersifat open source atau bebas digunakan, dimodifikasi, diperbaiki dan didistribusikan oleh para pembuat ataupun pengembang perangkat lunak. Dengan sifat open source perusahaan teknologi bebas menggunakan $O S$ ini diperangkatnya tanpa lisensi alias gratis.

\section{METODE PENELITIAN}

\subsection{Algoritma $A^{*}$}

Algoritma $A^{*}$ merupakan algoritma best first search yang melakukan perhitungan satu persatu pada tiap simpul untuk memperoleh lintasan terpendek pada suatu graf. Ketika seluruh lintasan telah selesai di hitung, algoritma $A^{*}$ akan memeilih lintasan yang paling pendek. Biaya yang diperhitunkan didapat dari biaya sebenarnya di tambah dengan biaya perkiraan.

\subsection{Sinopsis Game "Security Makam Belanda"}

Jepri adalah seorang pengangguran yang baru saja mendapatkan pekerjaan menjadi seorang penjaga makan di kuburan kuno belanda menggantikan sementara penjaga lama yang sedang mengambil libur. Namun, karena penjaga lama sangat terburuburu saat berangkat dia lupa meberi tau hal terpenting saat menjaga makam tersebut. Dimalam pertama nya si jepri menjaga makam tersebut dia tidak tau bahwa setiap malam mayat dan roh yang bergentayangan di tempat itu akan bangkit dan berusaha keluar dari komplek kuburan tersebut. Semu tergantung pada jepri untuk menjaga agar roh dan mayat tersebut tidak keluar dari komplek makam tersebut dengan bantuan sekop untuk bertahan hingga pagi. 


\subsection{Story Board Game "Security Makam Belanda"}

Story Board adalah diagram yang menjelaskan alurcerita dari sebuah rancangan cerita dari sebuah game, film, dan lain-lain. Story board disisni berisi tetang alur cerita game "Security Makam Belanda" pada Tabel 1.

Tabel 1 Story Board

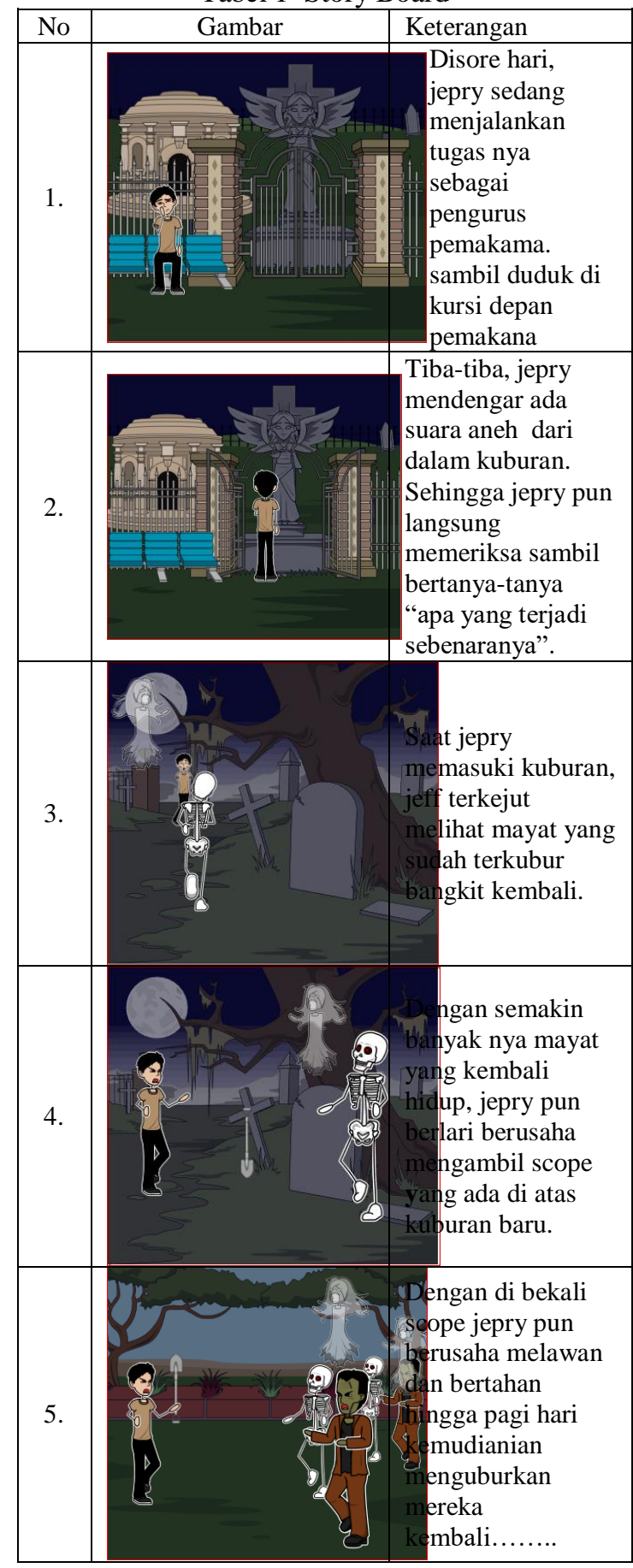

\subsection{Properti Asset}

Property asset disini berisi daftar asset yang di gunakan dalam pembuatan game "Security Makam Belanda"ini. Berikut daftar asset pada Tabel 2.
Tabel 2 Asset Game

\begin{tabular}{|c|c|c|}
\hline No & Keterangan & Tampilan \\
\hline 1. & $\begin{array}{l}\text { Jepri(player). } \\
\text { Karakter ini di } \\
\text { gunakan dan di } \\
\text { kendalikan oleh si } \\
\text { player dimana } \\
\text { karakter ini akan } \\
\text { berusaha bertahan } \\
\text { hingga pagi hari } \\
\text { menggunakan shovel. }\end{array}$ & \\
\hline 2. & $\begin{array}{l}\text { Mayat } \\
\text { Hidup(Enemy1). } \\
\text { Mayat hidup ini } \\
\text { adalah musuh pertama } \\
\text { yang di hadapi player. } \\
\text { mayat hidup ini } \\
\text { mempunyai kecepatan } \\
\text { yang lebih pelan dari } \\
\text { pada si jepri }\end{array}$ & \\
\hline 3. & $\begin{array}{l}\text { Tengkorak(Enemy2). } \\
\text { Tengkorak adalah } \\
\text { musuh yang akan di } \\
\text { temui player pada } \\
\text { level } 2 . \text { Tengkorak ini } \\
\text { mempunyai } 2 \text { kali } \\
\text { kecepatan player. }\end{array}$ & $=1$ \\
\hline 4. & $\begin{array}{l}\text { Arwah Penasaran } \\
\text { (Enemy3). } \\
\text { Arwah penasaran } \\
\text { adalah musuh terakhir } \\
\text { yang di temui player. } \\
\text { dimana arwah } \\
\text { penasaran bergerak } \\
\text { lebih cepat } \\
\text { dibandingkan dengan } \\
\text { kedua musuh } \\
\text { sebelumnya. }\end{array}$ & \\
\hline
\end{tabular}

\subsection{Flowchart}

Flowchart disini menjalankan garis besar bagaimana keseluruhan permainan berjalan

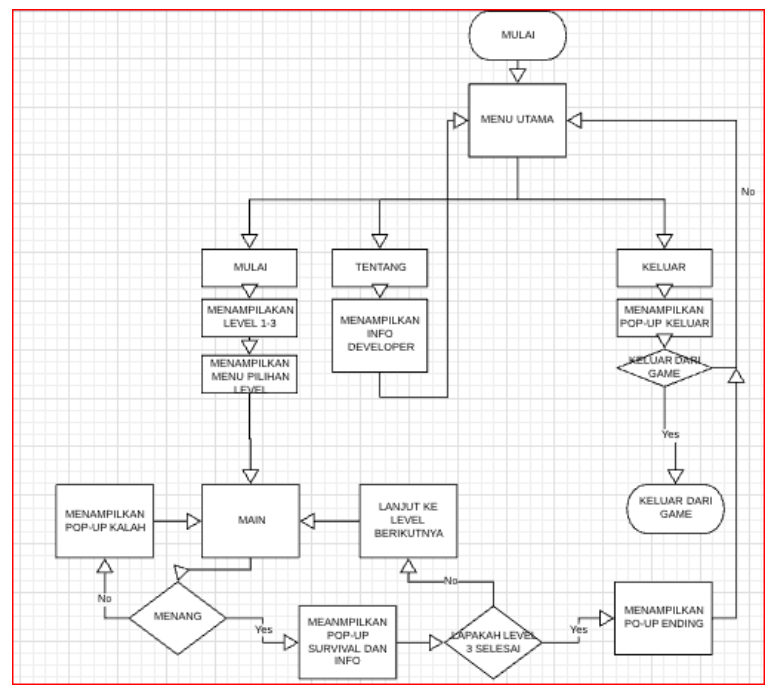

Gambar 1 Flowchart Keseluruhan Permainan 
Berdasarkan pada flowchar Gambar 1, penulis menggambarkan keseluruhan game dari layar menu hingga layar menang dan kalah.

\section{HASIL DAN PEMBAHASAN}

\subsection{Implementasi Hasil}

Implementasi dari pembuatan aplikasi game turbase action horror "Securyti Makam Belanda" dimana di sini menguji seluruh aplikasi dari awal yaitu menu hingga akhir permainan. Disi pengimplementasian, penulis menggunakan beberapa HandPhone berbasis adroid dengan spesifikasi yang berbeda-beda.

\subsection{Implementasi Pada User}

Implementasi disini mengetes bagai mana fungsi controller dan menu pada game apakah sudah sesuai dengan yang penulis inginkan.

\subsubsection{Implementasi Menu Utama}

Menu utama disini (Gambar 1) menampilkan tiga tombol pilihan yaitu Main, Tentang, dan Keluar. Dimana jika tombol Main ditekan maka akan membawa si pemain menuju halaman pemilihan level dari malam pertama sampai malam terakhir. Tombol tentang jika di tekan maka akan mengarah pada tampilan tentanfg data diri penulis.

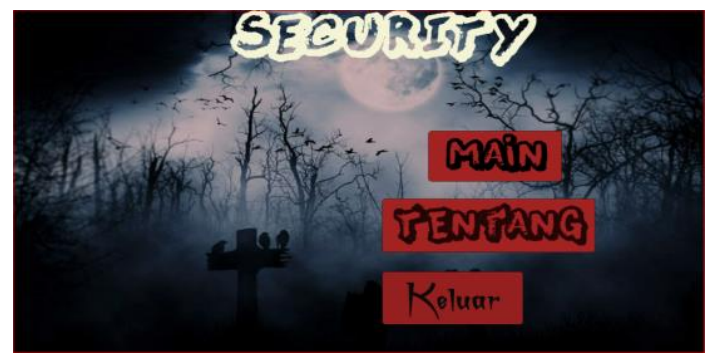

Gambar 1 Tampilan Menu Awal

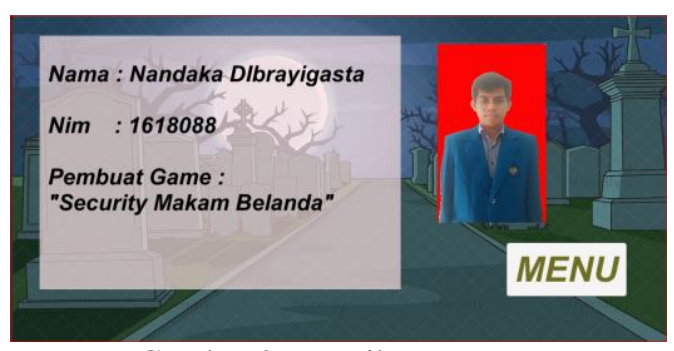

Gambar 2 Tampilan Tentang

\subsubsection{Implementasi Menu Pilihan Level}

Pada menu pilihan level( Gambar 3) terdapat empat tombol yaitu tombol Malam 1, Malam 2, Malam 3, dan Menu. Fungsi masing-masing dari ke empat tombol tersebut yaitu., tombol Malam 1, Malam 2, Dan Malam 3 jika di tekan maka akan menuju Map 1 Level 1 dimana pemain dapat langsung memainkan level tersebut hingga selesai.

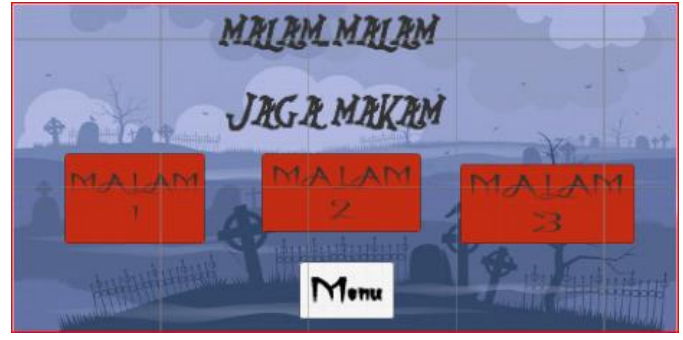

Gambar 3 Tampilan Pilih Level

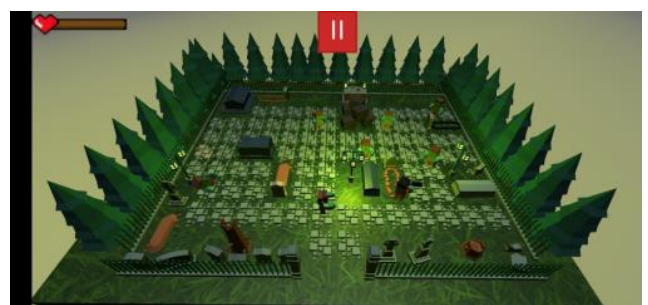

Gambar 4 Tampilan Pilih Level 1 Malam 1

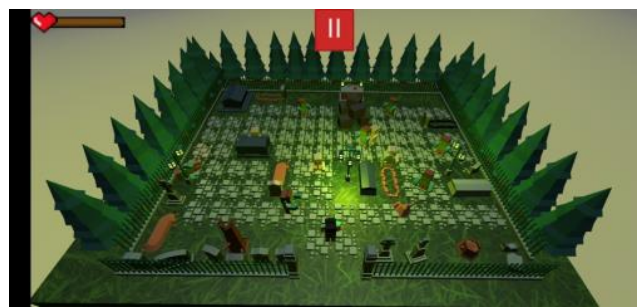

Gambar 5 Tampilan Pilih Level 2 Malam 2

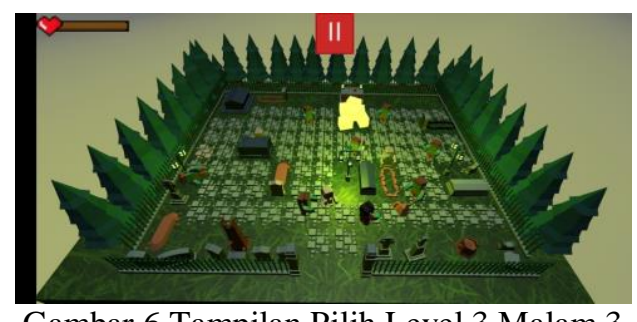

Gambar 6 Tampilan Pilih Level 3 Malam 3

\subsubsection{Implementasi cutsceen dan info}

Scene disini berisi tentang cerita si jepri dan juga info pengetahuan tentang 3 adat pemakaman yang berasal dari Bali, Kalimantan, dan Papua. Berikut cutsceen cerita dan info yang berada di dalam Game "Security Makam Belanda" :

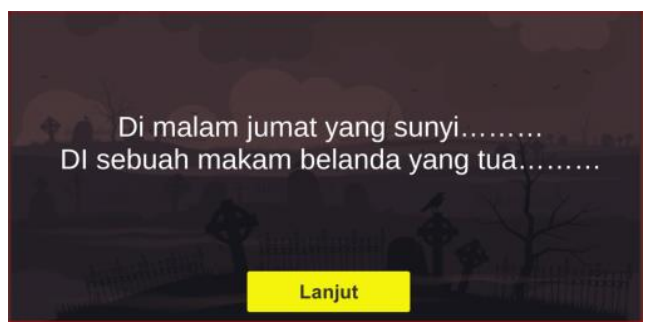

Gambar 7 Tampilan sceen opening 1 


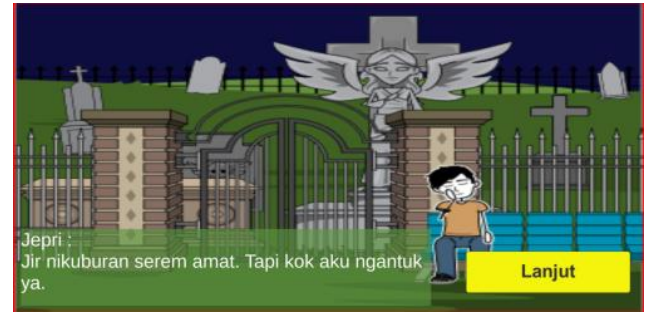

Gambar 8 Tampilan sceen opening 2

Scene opening ini akan terbuka jika pemain menekan tombol malam 1(Gambar 7 dan 8). didalam sceen ini akan menampilkan dialog pembuka cerita dari makam belanda dan juga awal mula pembukaan cerita si jepri sendiri.

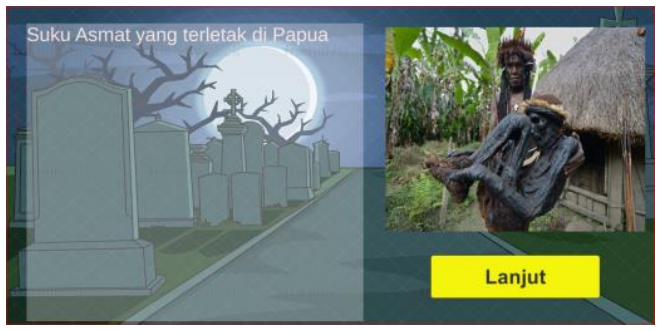

Gambar 9 Tampilan info asmat

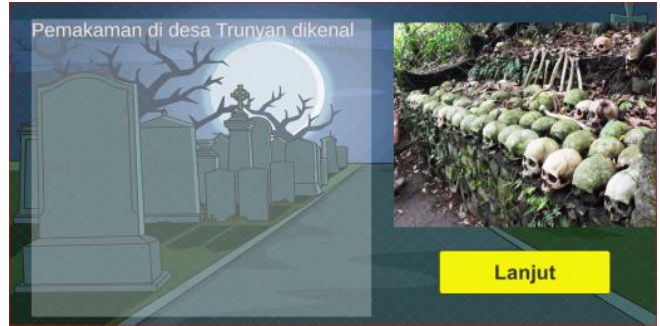

Gambar 10 Tampilan info trunyan

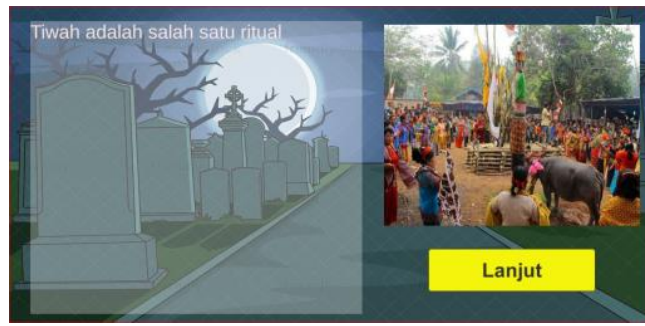

Gambar 10 Tampilan info tiwah

Scene info adalah scene yang menampilkan informasi tentang budaya pemakaman dari tiga daerah yang berkaitan dengan musuh yang ada di tiap level. Berikut scene info yand ada pada game "security Makam Cina" ini.

\subsubsection{Implementasi screen Survival dan Game Over}

Sceen ini hanya muncul jika beberapa sarat terpenuhi seperti, layar Game over(Gambar 11) hanya akan muncul jika nyawa(healbar) si character jepri sudah habis semua maka barulah layar game over muncul. Didalam layar Game over, terdapat 2 tombol yaitu replay dan menu. Jika tombol replay yang di tekan maka permainan akan memulai lagi dari awal. Namun jika tombol menu yang di tekan maka permainan akan kembali ke menu utama (Gambar 1).

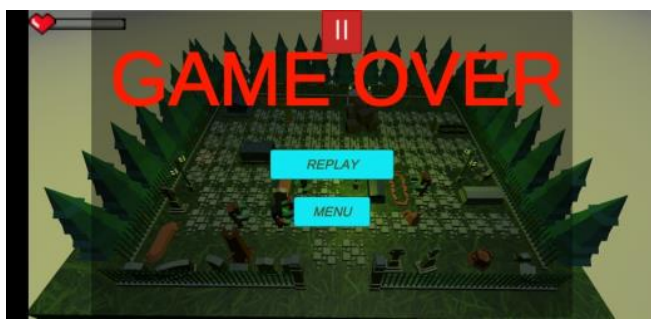

Gambar 11 Tampilan Game Over

Selanjutnya layar Survival. Layar ini juga hanya muncul jika beberpa sarat terpenuhi seperti, jika si character jepri dapat bertahan hingga pagi hari dan nyawanya(healbar) tidak habis sama sekali(minimal masih sisa 10 point). Jika sayarat tersebut terpenuhi, maka layar survival akan muncul.

Didalam layar survival(Gambar 12) terdapat dua tombol yaitu tombol Malam berikutnya dan Menu. Fungsi dari tombol menu adalah jika di tekan maka akan kembali ke menu utama. Sedangkan jika tombol Malam Berikut nya ditekan maka akan membawa user ke level atau malam selanjutnya.

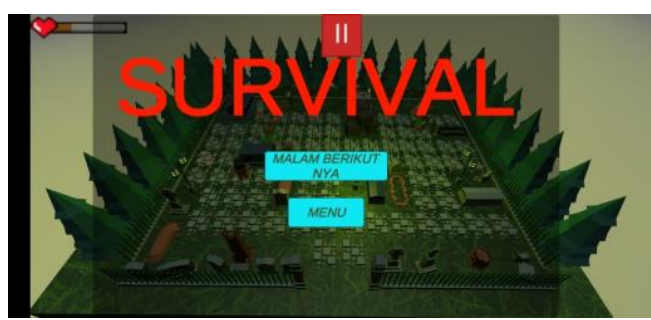

Gambar 12 Tampilan Survival

\subsection{Pengujian AI(Artificial Intelegence)}

Musuh atau Enemy dalam game ini mempunyai AI agar dapat bertindak mandiri dalam memutuskan dan mencari di mana letak player, jalan terdekat menuju player, dan memutar badan agar menghadapa player. berikut table pengujian AI pada Enemy.

\subsubsection{Pengujian Grid pada map}

Grid di sini di buat untuk menghasilkan sebuah node yang mana node tersebut digunakan untuk menghitung jarak terdekat oleh algoritma $\mathrm{A}^{*}$ berikut gambar Grid yang sudah di buat pada map. 
Tabel 3 Pengujian grid

\begin{tabular}{|l|l|l|}
\hline No & \multicolumn{1}{|c|}{ Status } & Hasil \\
\hline 1. & $\begin{array}{l}\text { Menggambar grid } \\
\text { pada Map }\end{array}$ & Berhasil \\
\hline 2. & $\begin{array}{l}\text { Membedakan node } \\
\text { yang bisa di lewati } \\
\text { dengan node yang } \\
\text { tidak bisa di lewati }\end{array}$ & Berhasil \\
\hline 3. & $\begin{array}{l}\text { Menentukan posisi } \\
\text { awal } \text { enemy dan } \\
\text { player } \text { pada node }\end{array}$ & Berhasil \\
\hline 4. & $\begin{array}{l}\text { Menentukan nilai tiap } \\
\text { node pada grid }\end{array}$ & Berhasil \\
\hline
\end{tabular}

\subsubsection{AI A* pada enemy}

Ai A* disini berfungsi untuk menghindari rintangan dan halangan dan juga menghitung jarak terdekat dari enemy ke jepri di dalam map yang sudah di buat.

Tabel 4 Pengujian AI A*

\begin{tabular}{|l|l|c|}
\hline No & \multicolumn{1}{|c|}{ Status } & Hasil \\
\hline 1. & $\begin{array}{l}\text { Menentukan jalur antara } \\
\text { enemy dan jepri }\end{array}$ & Berhasil \\
\hline 2. & $\begin{array}{l}\text { Menghitung jarak terdekat } \\
\text { antara enemy ke jepri }\end{array}$ & Berhasil \\
\hline
\end{tabular}

\subsection{Pengujian Fungsional}

Pengujian fungsioanal adalah pengujian mengenai proses fungsioanal yang terjadi dalam game. hasil pengujian dapat dilihat pada tabel 5 .

Tabel 5 Pengujian Fungsional

\begin{tabular}{|c|c|c|c|}
\hline \multirow{2}{*}{ No } & \multirow{2}{*}{ Item Uji } & \multicolumn{2}{|c|}{ Hasil } \\
\hline & & Berhasil & Gagal \\
\hline 1 & Menu Utama & $\sqrt{ }$ & - \\
\hline 2 & Button Main & $\sqrt{ }$ & - \\
\hline 3 & Button Tentang & $\sqrt{ }$ & - \\
\hline 4 & Buton Keluar & $\sqrt{ }$ & - \\
\hline 15 & Button Replay & $\sqrt{ }$ & - \\
\hline 6 & Button Menu & $\sqrt{ }$ & - \\
\hline 7 & $\begin{array}{l}\text { Buton Malam } \\
\text { Selanjutnya }\end{array}$ & $\sqrt{ }$ & - \\
\hline 8 & Level 1 Malam 1 & $\sqrt{ }$ & - \\
\hline 9 & Level 2 Malam 2 & $\sqrt{ }$ & - \\
\hline 10 & Level 3 Malam 3 & $\sqrt{ }$ & - \\
\hline 11 & Bar Health Player & $\sqrt{ }$ & - \\
\hline 12 & $\begin{array}{l}\text { Hp player berkurang } \\
\text { ketika terkena } \\
\text { serangan }\end{array}$ & $\sqrt{ }$ & - \\
\hline 13 & $\begin{array}{l}\text { Musuh meyerang } \\
\text { pada jarak tertentu }\end{array}$ & $\sqrt{ }$ & - \\
\hline 14 & $\begin{array}{l}\text { Game over saat HP } \\
\text { player } 0 \%\end{array}$ & $\sqrt{ }$ & - \\
\hline 15 & $\begin{array}{l}\text { Survivalsaat palyer } \\
\text { bertahan hingga pagi }\end{array}$ & $\sqrt{ }$ & - \\
\hline
\end{tabular}

\subsection{Pengujian Control Player dan Penginstalan}

Pengujian control player adalah pengujian touch control pada setiap HandPhone Adroid yang di istalkan aplikasi "securyti Makam Belanda" . berikut table pengujian nya pada table 6 .

Tabel 6 Pengujian AI Charakter

\begin{tabular}{|c|c|c|c|c|}
\hline \multirow{2}{*}{$\begin{array}{c}\text { Sistem } \\
\text { operasi }\end{array}$} & \multirow{2}{*}{ RAM } & $\begin{array}{c}\text { Status } \\
\text { Install }\end{array}$ & $\begin{array}{c}\text { Touch } \\
\text { Control }\end{array}$ & $\begin{array}{c}\text { Keteran } \\
\text { gan }\end{array}$ \\
\hline Android 10 & $6 \mathrm{~GB}$ & $\checkmark$ & Sesuai & Normal \\
\hline Android 9 & $4 \mathrm{~GB}$ & $\checkmark$ & Sesuai & Normal \\
\hline Android 9 & $6 \mathrm{~GB}$ & $\checkmark$ & Sesuai & Normal \\
\hline Android 10 & $6 \mathrm{~GB}$ & $\checkmark$ & Sesuai & Nomal \\
\hline Android 9 & $4 \mathrm{~GB}$ & $\checkmark$ & Sesuai & Normal \\
\hline
\end{tabular}

\subsection{Pengujian Pada User}

Pengujian pada user atau kuisioner dilakukan untuk mengetahui kepuasan pengguna dalam mengimplementasikan aplikasi game" Security Makam Belanda tampilan aplikasi, dan respond kemudahan menggunakan aplikasi. Pengujian pengguna di lakukan kepada 10 orang responden. Hasil dari pengujian pengguna dapat di lihat pada Tabel 7

Tabel 7 Pengujian pada User

\begin{tabular}{|c|c|c|c|c|}
\hline \multirow[b]{2}{*}{ No } & \multirow[b]{2}{*}{ Pertanyaan } & \multicolumn{3}{|c|}{ Respond Pengguna } \\
\hline & & Baik & $\begin{array}{c}\text { Cukup } \\
\text { Baik }\end{array}$ & Kurang \\
\hline 1. & $\begin{array}{l}\text { bagaimana } \\
\text { gameplay dalam } \\
\text { game "security } \\
\text { Makam Belanda" ? }\end{array}$ & $80 \%$ & $20 \%$ & - \\
\hline 2. & $\begin{array}{l}\text { Bagaiman control } \\
\text { dalam game } \\
\text { "security makam } \\
\text { belanda" ? }\end{array}$ & $78,6 \%$ & $21,4 \%$ & - \\
\hline 3. & $\begin{array}{l}\text { Bagaimana Cerita } \\
\text { Pada Game } \\
\text { "security makam } \\
\text { belanda" ? }\end{array}$ & $57,1 \%$ & $42,9 \%$ & - \\
\hline 4. & $\begin{array}{l}\text { Bagaimana unsur } \\
\text { edukasi dalam } \\
\text { game "security } \\
\text { makam belanda" ? }\end{array}$ & $64,3 \%$ & $35,7 \%$ & - \\
\hline 5. & $\begin{array}{l}\text { bagaimana } \\
\text { penilainan anda } \\
\text { terhadap } \\
\text { keselurahan game } \\
\text { "security makam } \\
\text { belanda" ? }\end{array}$ & $66,7 \%$ & $33,3 \%$ & - \\
\hline
\end{tabular}




\section{KESIMPULAN DAN SARAN}

\subsection{Kesimpulan}

Setelah dilakukanya pengujian pada aplikasi Game "Securyti Makam Belanda" berbasis Android, maka penulis mendapatkan kesimpulan sebagai berikut :

1. Pengimplementasian Metode $A^{*}$ pada enemy dapat di jalankan sesuai harapan penulis.

2. Pembuatan apliaksi game berbasis android menggunakan bahsasa C\# dapat berjalan sesuai harapan penulis.

3. Pergerakan Ai enemy dan player di tiap map sudah sesuai dengan harapan penulis.

\subsection{Saran}

Berdasarkan penelitian yang telah dilakukan maka penulis dapat memberikan saran-saran untuk pengembangan selanjutnya karena penelitian ini masih terdapat banyak kekurangan, sehingga untuk penyempurnaan dapat ditambahkan :

1. Metode $A^{*}$ dapat di kebangkan lebih baik lagi dalam Enemy agar lebih responsip.

2. NavsMesh Pada karakter jaepri dapat lebih di kembangkan karena pada palikasi game yang penulis buat batasan pada apa yang bisa dilewati oleh player dan enemy sangat terbatas.

3. Desain leve yang lebih menarik dan penuh warna di butuhkan untuk menarik minat pemain.

\section{DAFTAR PUSTAKA}

$\begin{array}{llr}\text { [1] GIDEON } & \text { ADIPRANA } & \text { TIGOR } \\ \text { SIBURIAN.(2017) } & \text { Perancangan } & \text { Dan } \\ \text { Implementasi Artificial Intelegence Pada Game } \\ \text { Strategy Turn-Base Role Playing Game }\end{array}$

Menggunakan Algoritma A*. Fakultas Teknologi Informasi, Institut Teknologi Sepuluh Nopember, Surabaya

[2] R. M. (2007) Variasi Penggunaan Fungsi Heuristik Dalam Pengaplikasian Algoritma A*, Teknik Informatika, Institut Teknologi Bandung, Bandung

[3] Sejarah Dan Pengealan Bahasa C\#, https://www.kodepolitan.com/2012/07/04/sejara h c\#/ 13 Juni 2020

[4] Andre Lionel Sanjaya, regorius Satia Budhi, \& Liliana(2015) Pembuatan Turn Based Strategy Role Playing Game Menggunakan Unity Game Engine. Program Studi Teknik Informatika Fakultas Teknologi Industri Universitas Kristen Petra, Jl. Siwalankerto 121 - 131 Surabaya 60236

[5] Ronny Setiawan, Jeanny Pragantha, \& Darius Andana Hari(2018) Pembuatan Game RolePlaying Turn-based Dengan Sistem RockPaper_Scissors "GEVANGEN". Program Studi Teknik Informatika Fakultas Teknologi Informasi Universitas Tarumanaga, Jakarta

[6] Dedy Irawan, Joseph, Sonny Prasetio, Suryo Adi Wibowo, and Yosep Agus Pranoto. "PELATIHAN PEMBUATAN GAMEMENGGUNAKAN GREENFOOT." INDUSTRI INOVATIF 5, no. 2 (2015): 29-35.

[7] Baani, M.K.H.A., 2019. PENERAPAN METODE FINITE STATE MACHINE PADA GAME PRIDE OF BATTLE. JATI (Jurnal Mahasiswa Teknik Informatika), 3(1), pp.203210. 